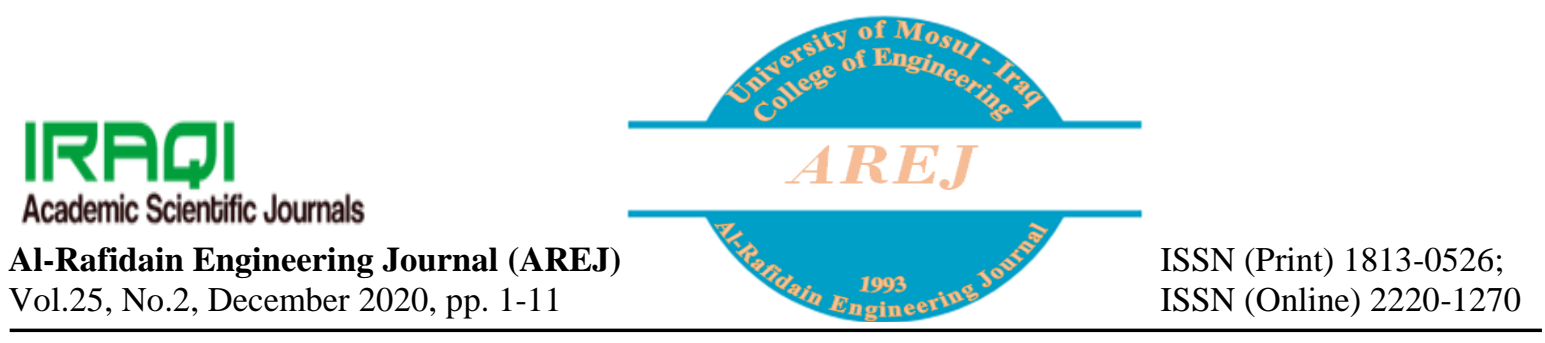

\title{
Numerical Investigation the Failure Mechanism of Left Slope of Darbandikhan Dam
}

\author{
Tareq H. AL-Rahal \\ tareqrahal73@gmail.com
}

\author{
Suhail I. Khattab \\ suhailkhattab@yahoo.com
}

Bayer J. Al-Sulaifanie

dr.bayar.alsulayvani@uomosul.edu.iq

Civil Engineering Department, Collage of Engineering, University of Mosul

Received: $25 / 1 / 2020$

Accepted: $25 / 7 / 2020$

\begin{abstract}
The aim of this research is to analyze the stability of the left shoulder slope of the Derbandikhan Dam failure due to rainfall and earthquake. This slope consists of unsaturated low plasticity clayey soil. All analyses were conducted by using the Geo-Studio program. The field survey was carried out for the study site and the soil samples were taken to perform the necessary laboratory tests to obtain the required soil properties. The field conditions (Rainfall and earthquake) were simulated, where the slope was exposed to rainfall at (24) $\mathrm{mm} /$ day intensity to various periods (10, 20,30, 40, 50 and 60) days. A slope stability analysis was performed at end of each period. Moreover, another analyses were performed by exposed slope to an earthquake at end of each rainfall period. Safety factor reached to critical value (1) when slope was exposed to the earthquake after (20) days of rain.
\end{abstract}

Keywords:

Left slope of the derbandikhan dam, Rainfall, Earthquake.

https://rengj.mosuljournals.com

Email: alrafidain_engjournall@uomosul.edu.iq

\section{INTRODUCTION}

Rainfall is important factor that reduces the slopes stability around the world. The soil slopes are unsaturated in general and when exposed to rainfall will cause changes in pore water pressure (suction), water flow and decrease shear strength of soil mass. These were main important parameters related directly with slope stability analyses of unsaturated soil which its surface influence by infiltration and evaporation [1] and [2]. The sources of a dynamic load may be natural, such as earthquakes, or they may be the result of human activities like vibration machines and railways. There are many instruments and types of equipment that can be used to monitor the response of slopes when exposed to earthquakes and to determine the degree of risk experienced by analyzing recorded data. In the absence of these instruments, the numerical analyses of slope stability by using the geotechnical software ( such as GEO-SLOPE) can be used. The laboratory models may be utilized to simulate the behavior of slopes during earthquakes such as a shaking table and centrifuge model [3], [4], [5] and [6]. Several tests to clear the effect of water content on the slopes stability of Yodogawa-levee sand soil by using the physical centrifuge model were conducted by Higo et. al.(2015)[7] . Ghayoomi and Mirshekari (2017) have calculated the effect of soil moisture content on the soil dynamic response when exposed to earthquakes. Srilatha, et al. (2016)[6] have a study to demonstrate the effect of the type and quantity of reinforcement on the seismic response (amplification of acceleration and horizontal displacement) of the unsaturated soil slope. Mohammed (2018) 
manufactured a laboratory model with $(2000 \times$ $1400 \times 1580) \mathrm{mm}^{3}$ in dimensions to study the effect of static loads on the stability of soil slope, they used two unsaturated soils types $(\operatorname{clay}(\mathrm{CH})$ and silt(ML)). Chuong (2019) conducted a field study on in arid and semi-arid climatic regions in northern Taiwan. Soil in these areas is called lateritic soil and classified as low plasticity clay.

Darbandikhan dam is located at southeast of AL-Sulaimaniyah about (55) $\mathrm{km}$ and nearby Darbandikhan city. This city is surrounded by a mountainous area, that is located at left and right sides of the Cerwan( upstream for Diala River). The catchment area for this river is the surface water running from the northeastern parts of Iraq in Darbandikhan Lake figure 1. This figure shows the main mountains in this region which include Sagram, Zimnako and GolamIn the southwest, North and West. Moreover, there is a fault passing through the dam area as appear in figure 2. So, the likelihood of the probability of dam failure is increasing when it exposed to an earthquake. The dam region is classified as active seismically. The dam is designed to resist earthquake up to $(\mathrm{Mw}=6.5)$ at the Richter scale. In $12^{\text {th }}$ November, 2017 at $(9: 18) \mathrm{pm}$, the dam was exposed to an earthquake in $(\mathrm{Mw}=7.3)$ magnitude at the epicenter of this earthquake ( the Azkla village, in the Iranian city of SarpoleZahab, about (30) $\mathrm{km}$ from the Darbandikhan dam, figure 3$)$. This earthquake caused (0.5) $\mathrm{m}$ settlement in the connection part, appearance of a big cracks on the road, located above the dam and failure in the left shoulder slope of this dam as shown in figure 4 . Then the sliding soil mass with rocks were fall in the lake and the accumulation clay prevented opening the gates of this dam. These factors caused a rise the water level in the lake and the dam exposed to an immense probability of collapse(personal communication with the chief geologists of this dam Mr. AbuBakr.). Therefore, it's important to evaluate the stability of the soil slope under various field conditions of this region such as static load(rock), earthquake and rainfall.

The aims of this search is to assess the stability of the left bank of the Darbandikhan dam, which was subjected to collapse and assign the conditions that caused failure.

\section{SITE INVESTIGATION}

To evaluate the soil slope stability for the left dam shoulder, a field survey of this location was conducted. Figure 4 shows this affected slope after exposing to Sarpole-Zahab earthquake. While, figure 5a displays the whole details for this slope.

It consists of two parts; the lower part has an inclination angle about $\left(71.56^{\circ}\right)$ and (15) $\mathrm{m}$ height (which was slipped during earthquake). The angle of the upper part is $\left(26.5^{\circ}\right)$ and extends to the crest at (1050) $\mathrm{m}$ above sea level of $10 \mathrm{~m}$ height. The horizontal base was supported with rock retaining a wall in (0.5) $\mathrm{m}$ width and (4) $\mathrm{m}$ height from the level of the road that separates slope from the dam lake. Figure $5 b$ explains the dimensions of the section which was adopted in all later analyses.

\section{LABORATORY TESTS}

To get the engineering properties for the soil slope under study, several samples were collected from a pit at (1) $\mathrm{m}$ depth from the surface of the slope. These samples were placed inside bags and brought to the Mosul University (Geotechnical Laboratory) to conduct the necessary tests. These tests involve index and chemical properties, granular analysis, soil classification, some mechanical properties and the standard compaction test, results presented in Table 1. Moreover, The grain size distribution curve for Darbandikhan soil was observed in figure 6 .

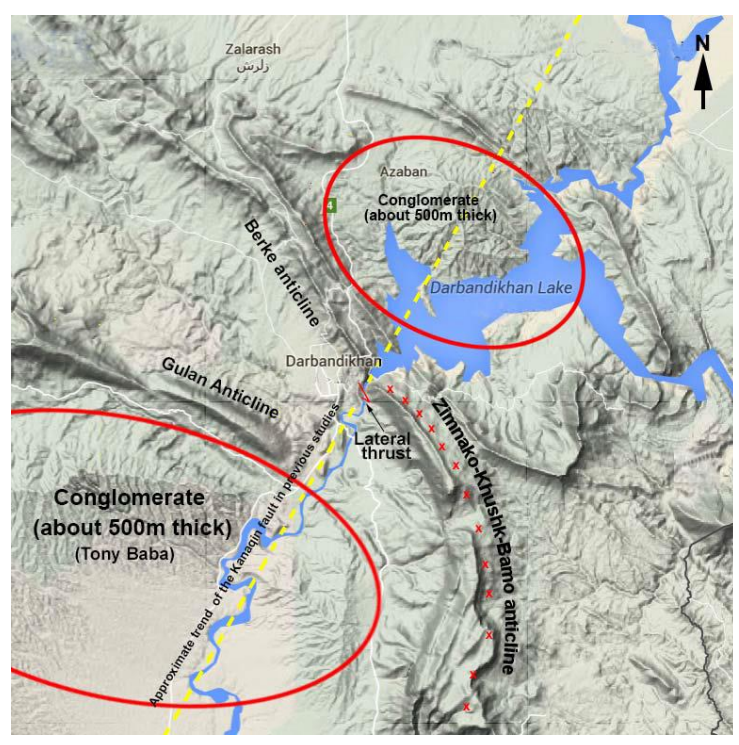

Fig. 1 Topographic map for the region around Darbandikhan city, [8]. 


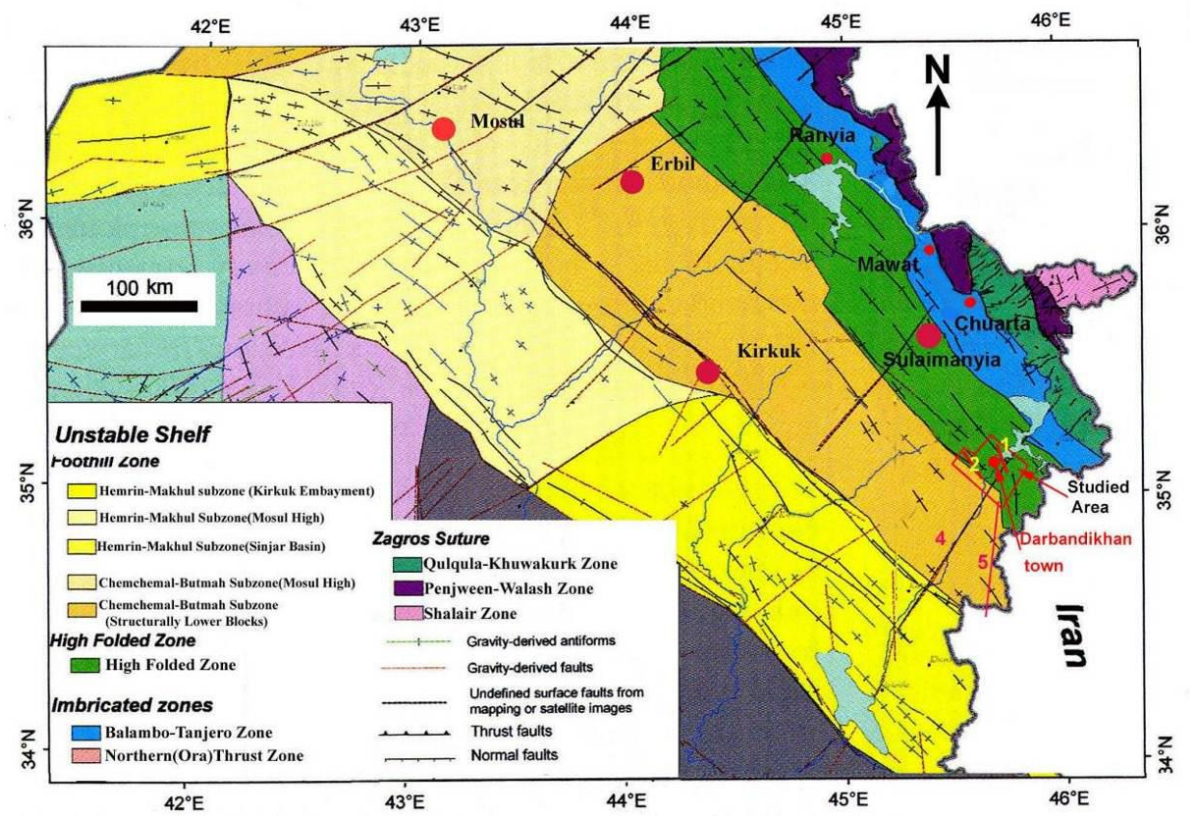

Fig. 2 Tectonic subdivision of the northern Iraq on which the Darbbandikhan dam area is shown with, 1, 2 are the two fault which studied by [8].

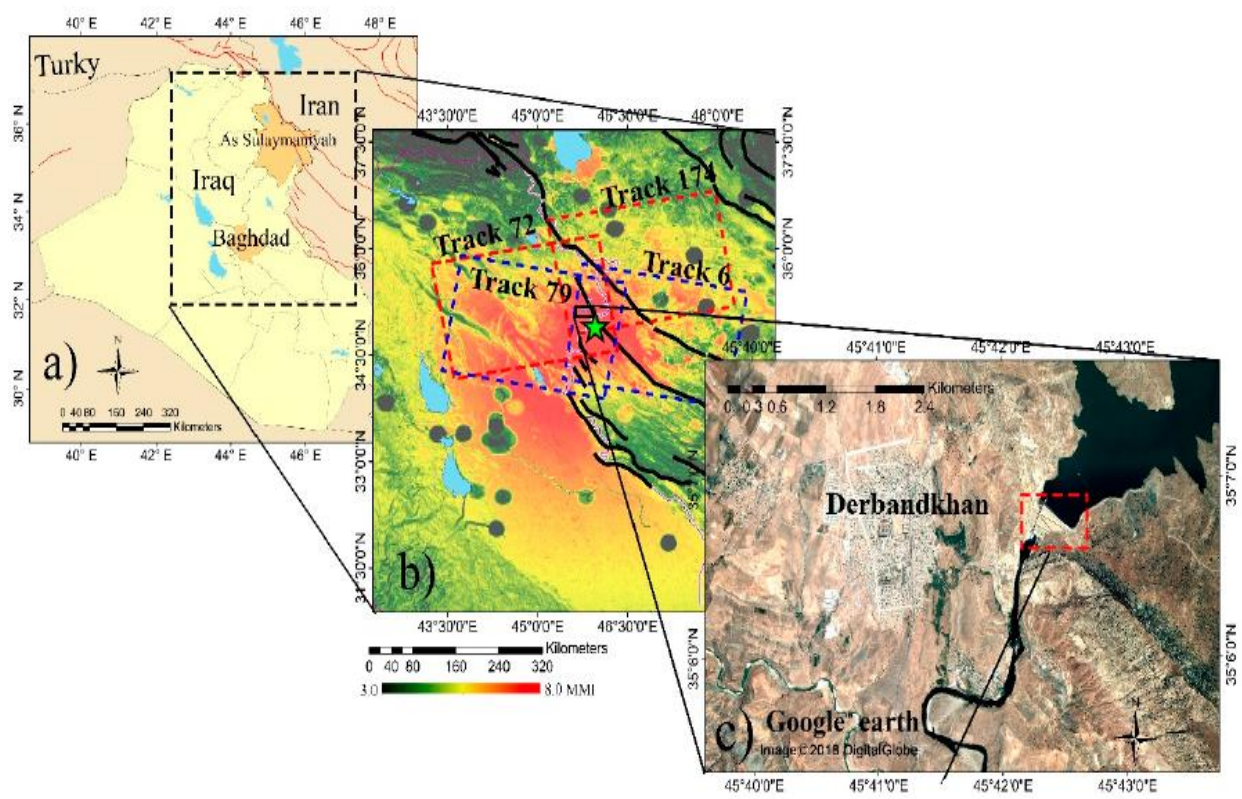

Fig. 3 The geological Darbandikhan dam area. (a-local Iraq map, b- shaking map of intensity, c-Darbandikhan dam location),[9]. 


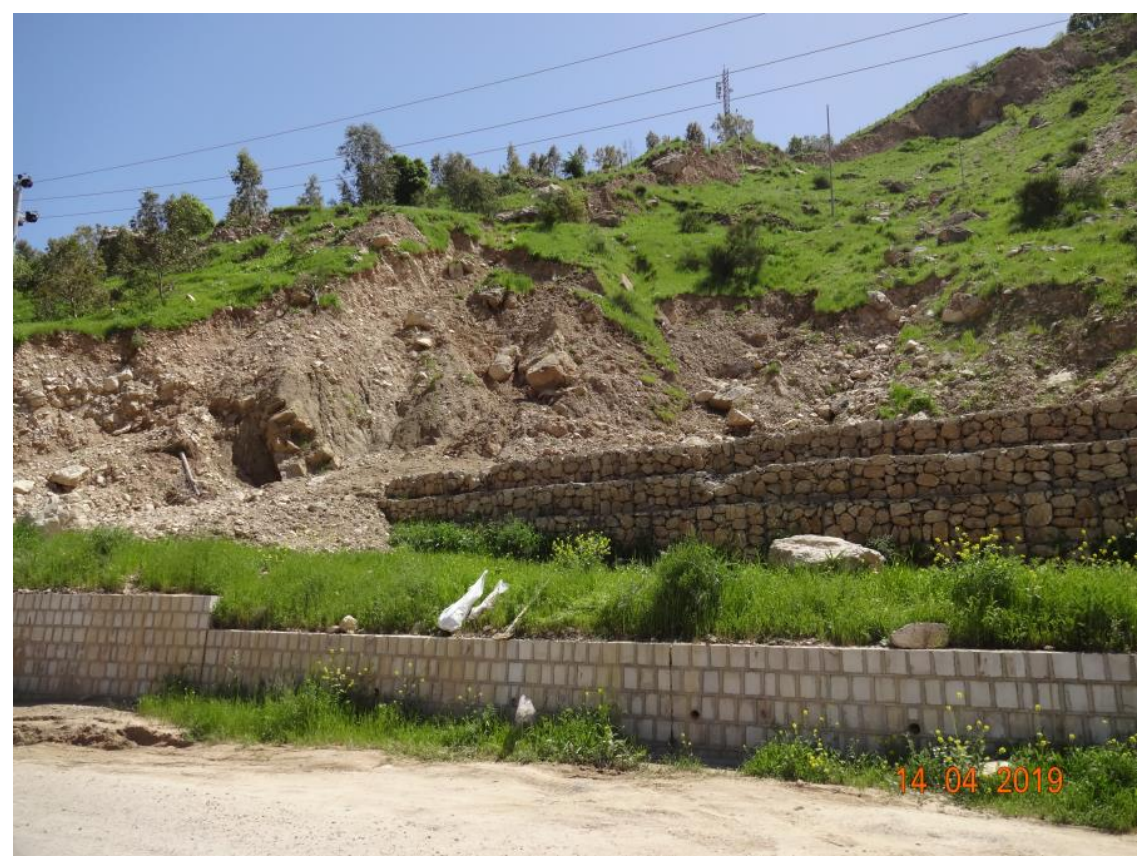

(b)

Fig. 4 The left shoulder of the Darbandikhan dam shows the part of the slope that failed during the earthquake).

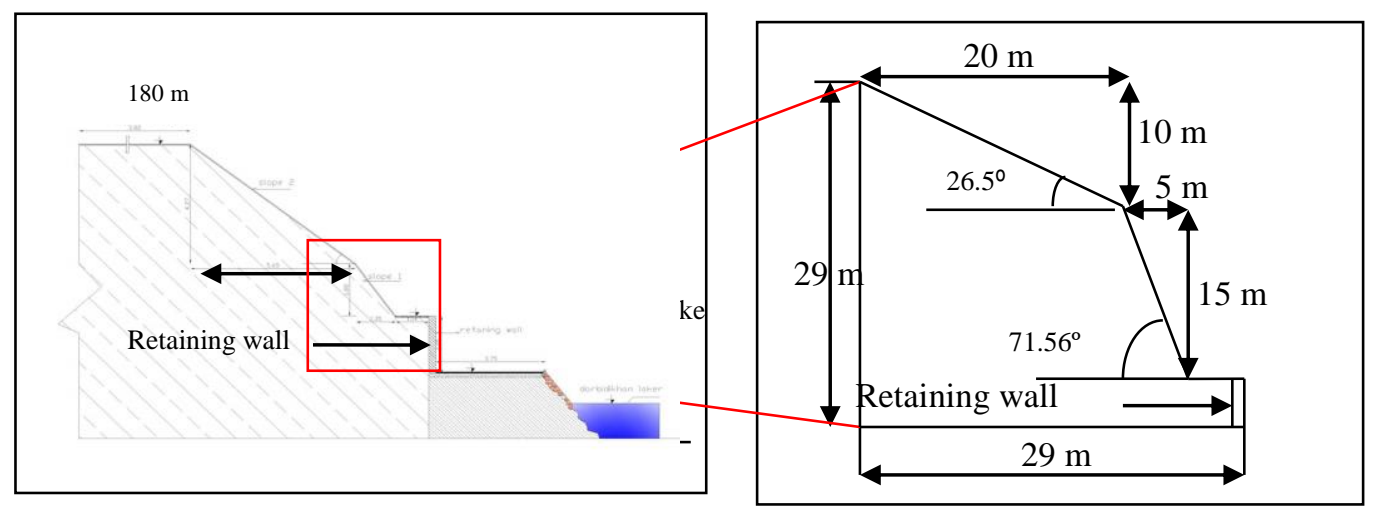

(a)

(b)

Fig. 5 Schematic diagram for the case study slope (a-Cross section of the left dam shoulder, b- part of the slope which exposed to failure). 
Table 1: Engineering Properties of the soil for left shoulder of Darbandikhan Dam.

\begin{tabular}{|c|c|c|c|}
\hline \multicolumn{3}{|c|}{ Engineering Properties } & Value \\
\hline \multirow{3}{*}{\multicolumn{2}{|c|}{ Atterberg limit }} & Liquid Limit(\%) & 46 \\
\hline & & Plastic Limit(\%) & 22 \\
\hline & & Plasticity Index(\%) & 24 \\
\hline \multicolumn{3}{|c|}{ Soil Classification } & $\mathrm{CL}$ \\
\hline \multicolumn{3}{|c|}{ Specific Gravity (Gs) } & 2.68 \\
\hline \multirow{4}{*}{\multicolumn{2}{|c|}{ Chemical Tests }} & Total soluble salts (T.S.S \%) & 4.2 \\
\hline & & Organic matter (\%) & 1.21 \\
\hline & & Sulphate Salts $\left(\mathrm{SO}_{3}\right)$ & 0.45 \\
\hline & & Gypsum content (\%) & 4.03 \\
\hline \multirow{3}{*}{\multicolumn{2}{|c|}{ Grain Size Analysis }} & Sand (\%) & 17 \\
\hline & & Silt (\%) & 51 \\
\hline & & Clay (\%) & 32 \\
\hline \multicolumn{3}{|c|}{ Activity=P.I/C } & 0.75 \\
\hline \multirow{2}{*}{$\begin{array}{l}\text { Compaction } \\
\text { Characteristic }\end{array}$} & \multirow{2}{*}{ Standard Compaction } & Max. dry unit weight $\left(\mathrm{kN} / \mathrm{m}^{3}\right)$ & 16.8 \\
\hline & & Optimum moisture content(\%) & 20 \\
\hline \multirow{2}{*}{\multicolumn{2}{|c|}{ Direct shear test }} & Effective cohesion, $\left(\mathrm{c}^{\prime}\right) \mathrm{kPa}$ & 25 \\
\hline & & $\begin{array}{l}\text { Effective angle of internal friction, } \\
\qquad\left(\varphi^{\prime}\right)\end{array}$ & 290 \\
\hline \multirow{2}{*}{\multicolumn{2}{|c|}{ Flow parameter (For soil at the saturated case) }} & $\mathrm{k}_{\mathrm{x}}(\mathrm{m} / \mathrm{sec})$ & $1.82 \mathrm{e}-7$ \\
\hline & & $\mathrm{k}_{\mathrm{y}}(\mathrm{m} / \mathrm{sec})$ & $1.82 \mathrm{e}-7$ \\
\hline \multicolumn{3}{|c|}{ Initial void ratio $\left(e_{i}\right)$} & 0.588 \\
\hline
\end{tabular}

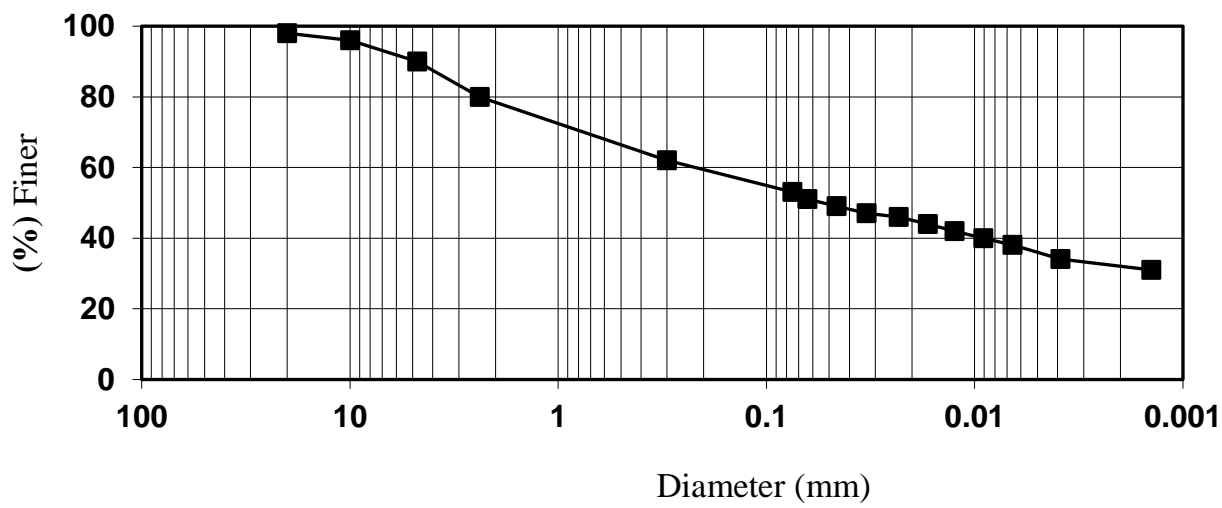

Fig. 6 Grain size distribution curve for Darbandikhan soil. 


\section{NUMERICAL ANALYSES AND RESULTS}

Figure 7 displays the boundary condition, geometry, and the finite element (F.E.) mesh properties of this case study. The various analyses were performed using Geo-Studio software. The width of the slope is (30) $\mathrm{m}$ and (29) $\mathrm{m}$ is height. Slope of this case has two different angles as revealed in figure 5. This shape simulates the natural slope failure in the dam site. The shape (Quads and triangles) was chosen for mesh elements. Fig. 8 shows the relation between global element size and factor of safety (FS) of the slope model. From this fig., the size at which FS remain approximately constant is(1) $\mathrm{m}$. This size represents the suitable mesh size, chosen for the simulated model. Moreover, to increase the accuracy at the influenced region with applied load (below the applied load), the size of elements is compressed to less than $(0$. 25)m. In nature, the slope is exposed to different environmental conditions and sustains the mass of some rock sliding at different sizes and shapes from the upper parts to the lower parts, rainfall at different intensities and durations in addition to earthquakes. Geo-Studio software was utilized to simulate previous conditions and to analyze the stability of the slope under one or more of these conditions. The SIGMA/W coupled Stress/PWP was used to simulate the static load condition. Static load was represented by a rock with dimensions $(1 \times 1 \times 3) \mathrm{m}$. The rainfall condition was simulated by SIGMA/W. The rainfall intensity was represented in the boundary conditions of these analyses. The parent of rainfall analyses is SIGMA/W coupled for static load, to provide a pore- pressure change from this parent. The elastic- plastic material model was used in these analyses to simulate the clayey soil behavior. The QUAKE/W analysis-Equivalent linear Dynamic is used to simulate the effect of earthquake on slope stability. In this couple(QUAKE/W), earthquake data (acceleration value with time during earthquake) is given as input in time section to show the effect of earthquake.

SLOPE/W Analysis utilized to analyze the stability of the slope to know the shape of the slip surface and FS of any previous analysis by making it parent for SLOPE/W analysis. The Mohr-Coulomb is utilized in SLOPE/W analysis to simulate soil behavior. Moreover, the SWCC was predicted by the software based on soil grains size distribution curve figure 9a [10]. Finally, the hydraulic conductivity function was predicted based on SWCC, saturated volumetric water content and residual degree of saturation
Figure 9b [11]. Table 2 shows some of the required soil parameters, conducted in the previous analysis. The void ratio $\left(\mathrm{e}_{\mathrm{o}}\right)$, degree of saturation(s) and the degree of saturation at saturated $\left(\mathrm{s}_{\mathrm{sat}}\right)$ were calculated by using the physical properties of the soil sample at unsaturated case. The poissons ratio was calculated by using worth equation for cohsive soil [12]. Finally, the damping ratio ( $\xi$ ) was calculated by using the expression that development by Kramer (1996) [13].

The slope stability analysis was studied considering the unsaturated case (suction=135 $\mathrm{kPa}$ which measured by using two indirect laboratory methods(saline solution and osmotic membrane) of the unsaturated soil samples). Figure 10 offers the critical slip surface shape and the safety factor (3.843) for this case. Later, rainfall was continuously applied at intensity (24) $\mathrm{mm} /$ day on the upper surface of the slope at various durations $(\mathrm{d}=10,20,30,40,50$ and 60$)$ days. Figure 11 shows the values of the pore water pressure (PWP) of soil after (60) day rainfall duration and at different depths. For the selected point, located at (2) $\mathrm{m}$ depth below the upper surface of the slope, the suction of the soil was decreased from (135 to 56) $\mathrm{kPa}$ at the end of the first rainfall period ( $\mathrm{d}=10$ days). Then, the PWP becomes positive and rise with increasing of the duration of rainfall until reaching $(189) \mathrm{kPa}$ at the end of the rainfall duration ( $\mathrm{d}=60$ day). Figures (12 to 17) explain the critical slip surface with factor of safety (FS) at the end of each rainfall period. Also, the obtained factor of safety decreases to(1.852) after (60) day rainfall.

At the end of each rainfall period, the slope was exposed to an earthquake in the same epicenter characteristics of sarpole-Zahab ( $\mathrm{Mw}=7.3$, duration $=30 \mathrm{sec}$ and Peak Ground Acceleration $=8.152 \mathrm{~g}$ ), which leads to failure. Figure 18 shows the change of FS during earthquake applied at end of each rainfall period. While, figure 19 explains the minimum FS of each rainfall period. From this figure, the slope failure is occurred with the earthquake application at the end of the second rainfall period (20day). 


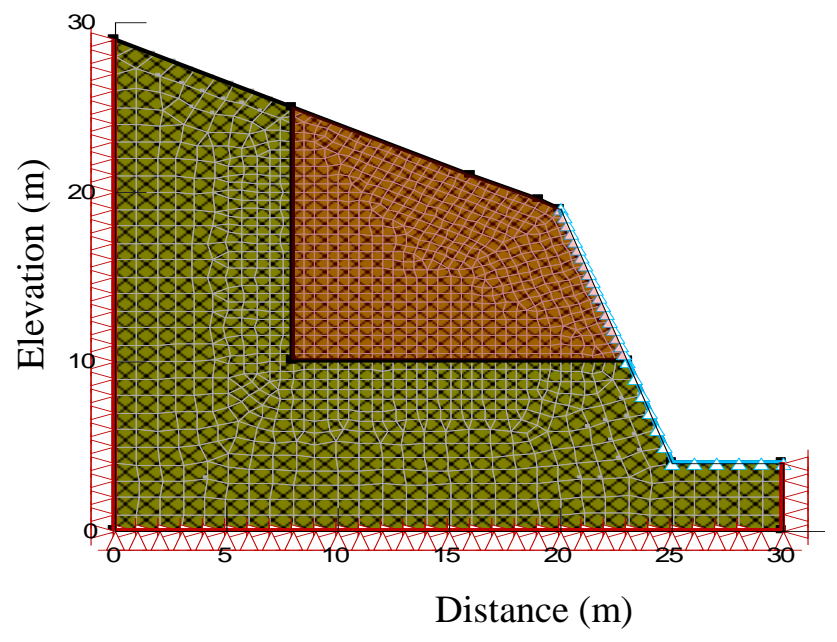

Fig. 7 Boundary condition and geometry of case. study

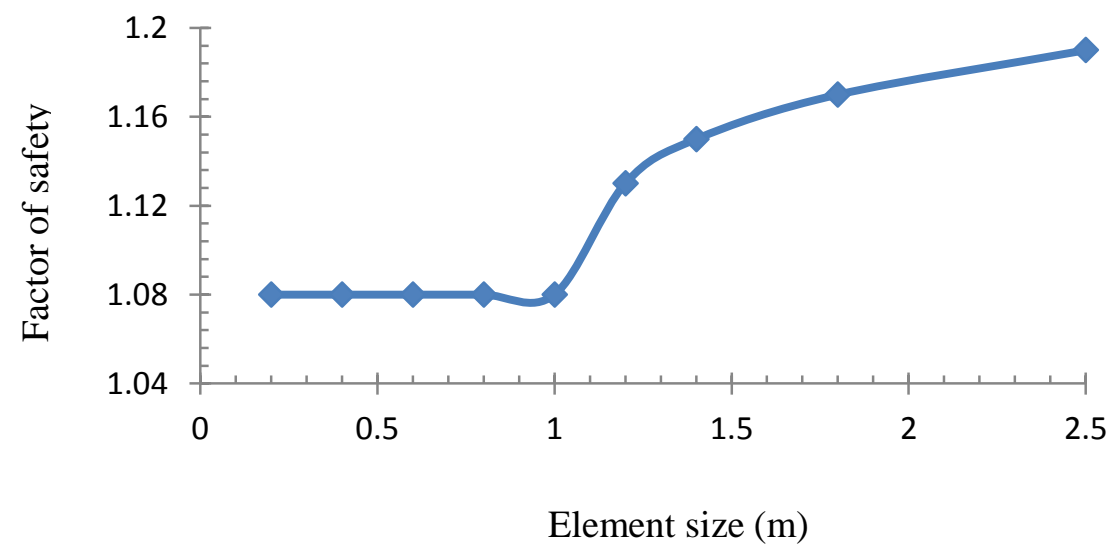

Fig. 8 The effect of element size on the FS of the slope.

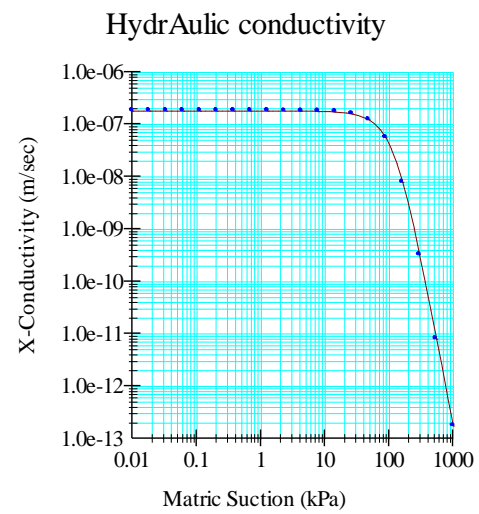

(a)

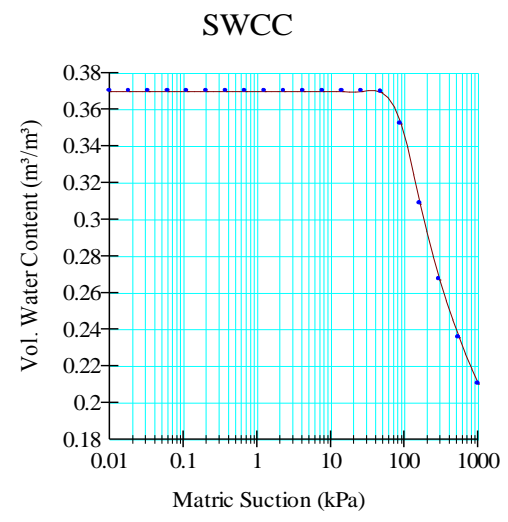

(b)

Fig. 9: a-Hydraulic conductivity and b-SWCC of soil case study. 
Table 2: Parameters of case studv

\begin{tabular}{|c|c|c|c|c|c|}
\hline \multicolumn{2}{|c|}{ General characteristics } & \multicolumn{2}{|c|}{ Parameter } & \multicolumn{2}{|c|}{ Flow parameter } \\
\hline Identification & $\begin{array}{l}\text { Low plasticity clay } \\
\text { (CL) }\end{array}$ & $\begin{array}{l}\text { Modulus of } \\
\text { elasticity (E) }\end{array}$ & $10 \mathrm{MPa}$ & Model & Van Genuchten \\
\hline \multirow{2}{*}{ Drainage type } & \multirow{2}{*}{ Drained } & \multirow{2}{*}{ c } & \multirow{2}{*}{$25 \mathrm{Kpa}$} & $\mathrm{S}$ & $88.3(\%)$ \\
\hline & & & & $\mathrm{S}_{\text {sat }}$ & $100(\%)$ \\
\hline$\gamma_{\mathrm{d}} \mathrm{kN} / \mathrm{m}^{3}$ & 16.8 & $\varnothing$ & $29^{\circ}$ & $\mathrm{k}_{\mathrm{x}} \mathrm{m} / \mathrm{s}$ & $1.82 \times 10^{-7}$ \\
\hline$\gamma_{\text {unsat }} \mathrm{kN} / \mathrm{m}^{3}$ & 20.16 & $K_{0}=1-\sin \varnothing$ & 0.515 & $\mathrm{k}_{\mathrm{y}} \mathrm{m} / \mathrm{s}$ & $1.82 \times 10^{-7}$ \\
\hline$\gamma_{\text {sat }} \mathrm{kN} / \mathrm{m}^{3}$ & 20.5 & $\begin{array}{c}\text { Damping ratio } \\
\text { (६) }\end{array}$ & 0.234 & $\psi$ & 135 \\
\hline $\mathrm{e}_{\mathrm{o}}$ & 0.588 & Poisons ratio & 0.31 & $\theta_{\mathrm{w}}$ & 0.32 \\
\hline
\end{tabular}

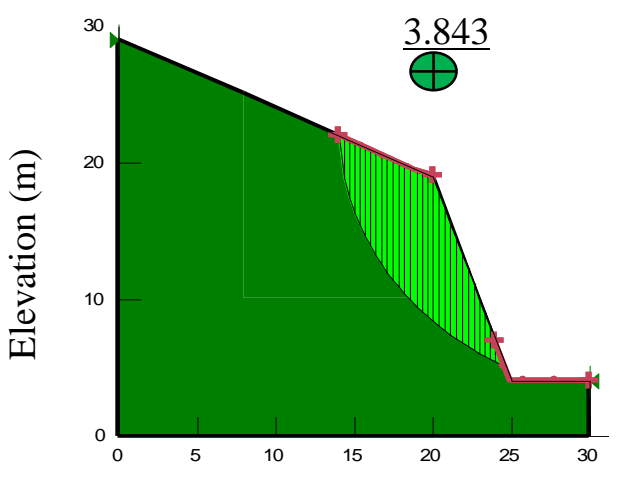

Distance (m)

Fig. $10 \mathrm{FS}$ and critical slip at unsaturated case.

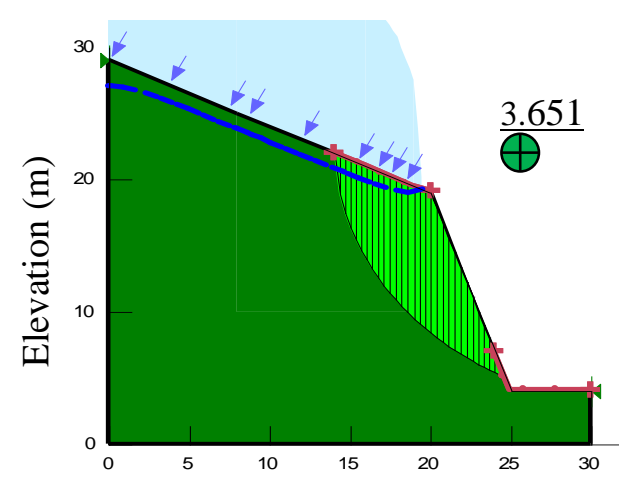

Distance (m)

Fig. 12 FS. subsequent to (10) day rainfall at (24) $\mathrm{mm}$ /day intensity.

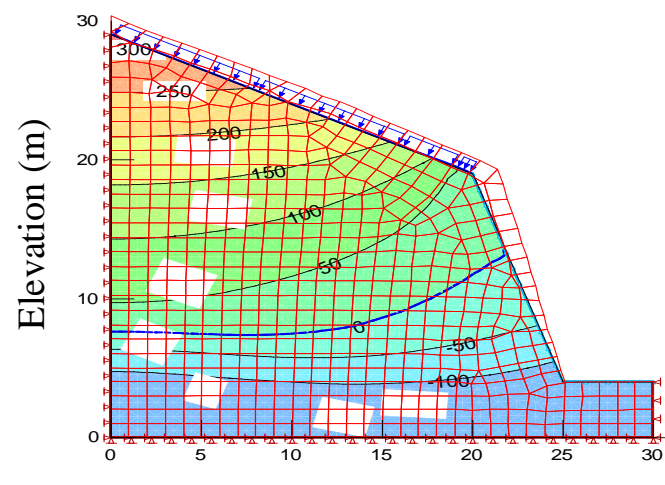

Distance $(\mathrm{m})$

Fig. 11 Pore water pressure contours subsequent to (60) day rainfall at (24) $\mathrm{mm}$ /day intensity.

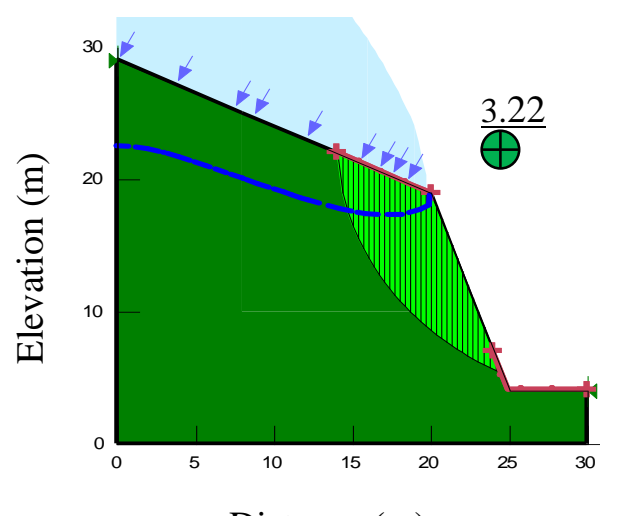

Distance (m)

Fig. 13 FS. subsequent to (20) day rainfall at (24) $\mathrm{mm}$ /day intensity. 


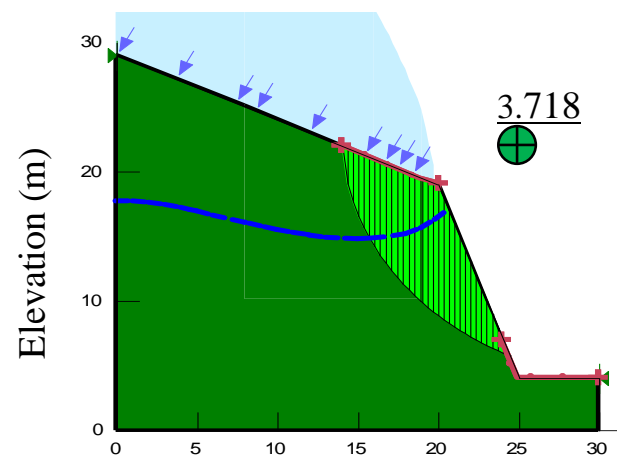

Distance (m)

Fig. 14 FS. subsequent to (30) day rainfall at (24) $\mathrm{mm} /$ day intensity.

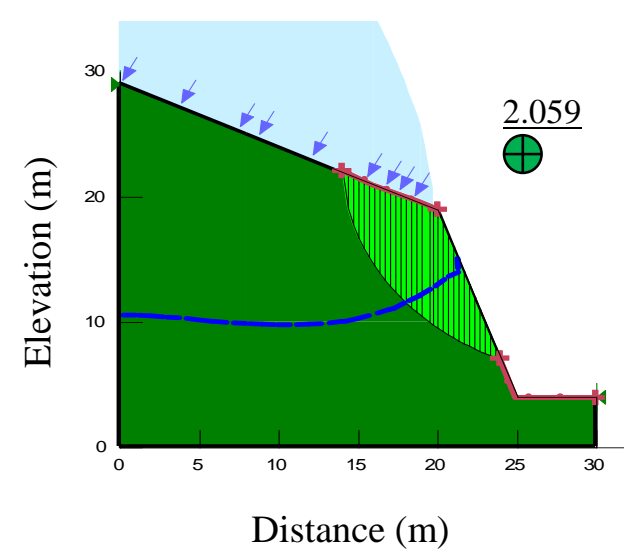

Fig. 16 FS. subsequent to (50) day rainfall at (24) $\mathrm{mm} /$ day intensity.

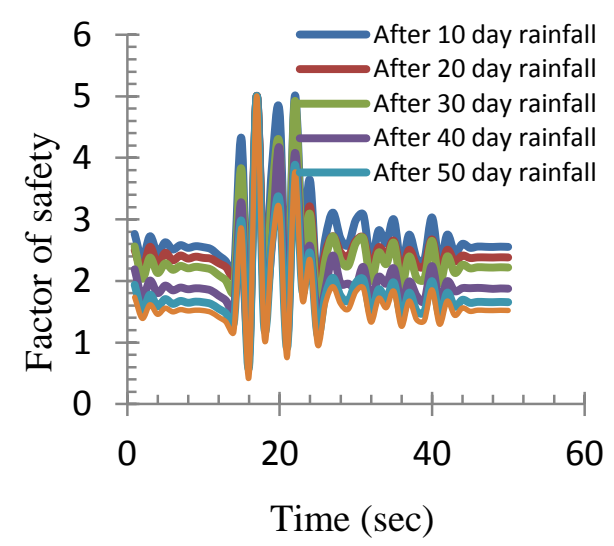

Fig. 18 Change FS for slope during applied earthquake after different rainfall duration.

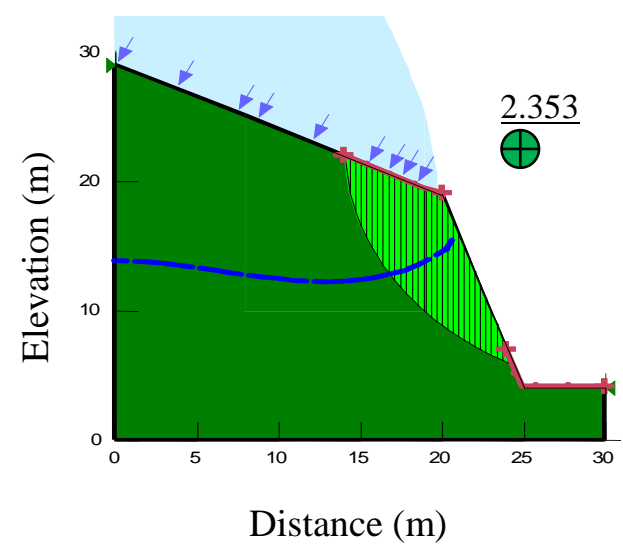

Fig. 15 FS. subsequent to (40) day rainfall at (24) $\mathrm{mm}$ /day intensity.

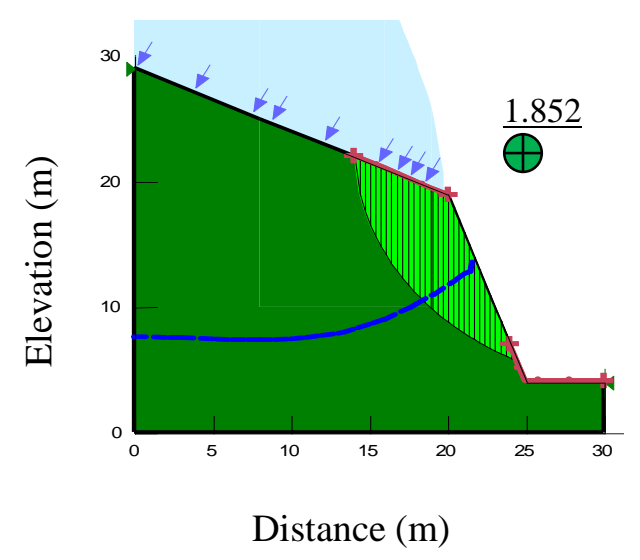

Fig. 17 FS. subsequent to (60) day rainfall at (24) $\mathrm{mm}$ /day intensity.

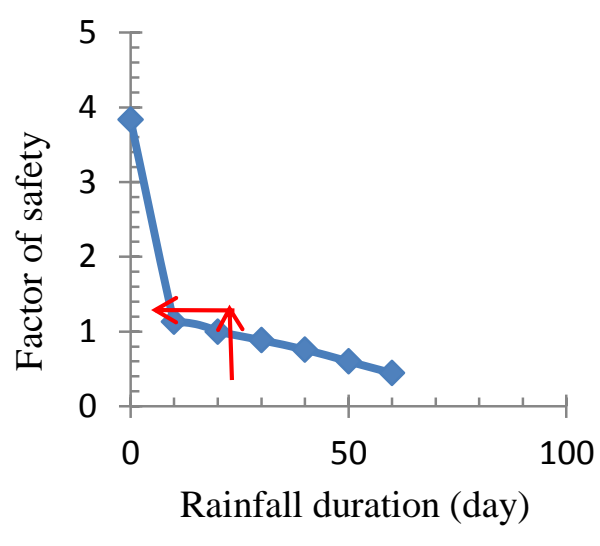

Fig. 19 Minimum FS for slope during applied earthquake after different rainfall duration 


\section{CONCLUSIONS}

The conducted analyses give the following conclusions:

1- The slope is stable in the case of unsaturated soil (factor of safty (FS) = 3.843).

2- Rainfall causes dissipation of soil suction then reduced the shear resistance and factor of safty (FS) to (1.82) after (60) day rainfall at (24) $\mathrm{mm} /$ day intensity.

3- Earthquake led to amplifying a generated stresses within the soil mass and then, reduces slope stability.

4- The analysis results showed the explanation of the site failure conditions occurred when slope is exposed to 20day rain at intensity $24 \mathrm{~mm} /$ day and then exposed to earthquake that has $\mathrm{Mw}=7.3$, duration= $30 \mathrm{sec}$ and Peak Ground Acceleration $=8.152 \mathrm{~g}$.

\section{REFERENCES}

[1] W.J. Cheng, G. X. Nan and S. M. Guo "Effects of Pore-water Pressure Distribution on Slope Stability under Rainfall", 2014; Infiltration. Journal of Electrical Geotechnical Engineering, Vol. 19, (Bund H), 1677-1685.

[2] A. Rahimi, H. Rahardjo and E.C. Leong "Effect of hydraulic properties of soil on rainfall-induced slope failure", 2010; Engineering Geology, Vol. 114, No. (3-4), pp. 135- 143.

[3] B.V.S. Viswanadham and R.R. Mahajan "Centrifuge model tests on geotextile reinforced slopes", 2007; Geosynthetics International, Vol. 14, No.6, pp. 365-379.

[4] D. Giri and A. Sengupta " Dynamic Behavior of Small-Scale Model Slopes in Shaking Table Tests", 2010; (Int J. Geot . Engg. 4,1 1-11.

[5] M. Vyas, S. Rukhaiyar and S. Mittal " Behavior of Slope under Dynamic Condition- An Experimental Study" , 2014; J. of Civil Eng. Research, 5(2), pp.122-128.

[6] N. Srilatha, L. G. Madhavi and C. G. Puttappa "Seismic Response of Soil Slopes in Shaking Table Tests: Effect of Type and Quantity of Reinforcement", 2016; (Int. J. of Geosynth. and Ground Eng, Vol. 33, pp. 2-13

[7] Y. Higo, C. Lee, T. Doi, T. Kinugawa, M. Kimura, S. Kimoto and F. Oka (2015) " Study of dynamic stability of unsaturated embankments with different water contents by centrifugal model tests", 2015; Soils and Foundations, Vol.55, No.1, pp.112-126.

[8] H. Karim, S. Al- Hakari and A. Kharajiany " Surface Analysis and Critical Review of the Darbandikhan (Khanaqin) Fault, Kurdistan Region, Northeast Iraq", 2016; Kurdistan Academics Journal (KAJ), Part - A -, Vol: 12, No.: 1, July 2016.

[9] Y. AL- Husseinawi, Z. Li, P. Clarke and S. Edwards "Evaluation of the Stability of the Darbandikhan Dam after the 12 November 2017 Mw 7.3 Sarpol-e Zahap (Iran-Iraq Border) Earthquake", 2018; Remote Sens. 10,1426; doi:10.3390/rs10091426.

[10] M. D Fredlund., G. W. Wilson, D. G. Fredlund, "Use of the Grain-Size Distribution for Estimation of Soil-Water Characteristic Curve", 2002; Canadian Geotechnical Journal, Vol. 39, p. $1103-1117$.

[11] D.G. Fredlund and H.Rahardjo "Soil Mechanics for Unsaturated Soils",1993; John Wiley and Sons, Incorporation, USA.

[12] B.M. Das (2008) "Advanced Soil Mechanics", 2008; Third Edition. Taylor and Franci. New York, USA.

[13] S. L. Kramer,(1996), "Geotechnical Earthquake Engineering, Prentice Hall", pp. 240. 


\title{
تحليل استقرارية منحدر الكتف الأيسر لسد دربنديخان الذي تعرض إلى الفشل
}

\author{
بيار جعفر السليفاني \\ dr.bayar.alsulayvani@uomosul.edu.iq \\ سهيل ادريس عبدالقادر خطاب \\ suhailkhattab@yahoo.com \\ طارق حسن محمد الرحال \\ tareqrahal73@gmail.com
}

جامعة الموصل ـ كلية الهندسة ـ قسم الهندسة المدنية

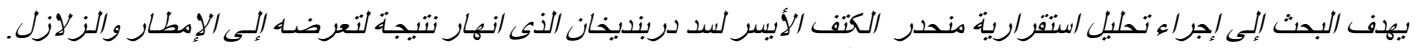

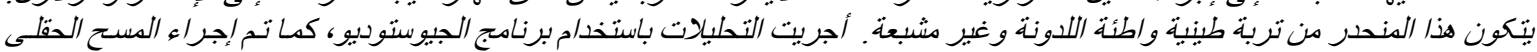

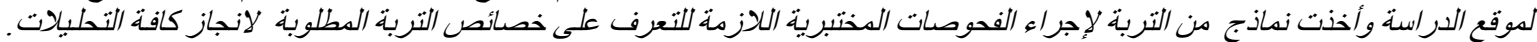

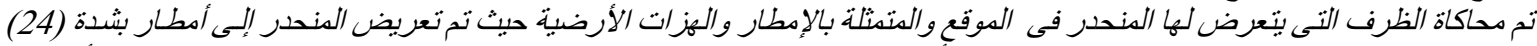

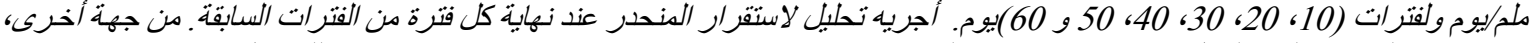

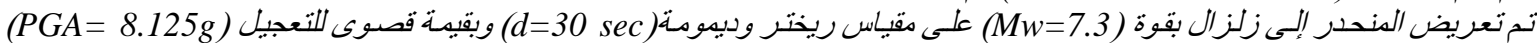

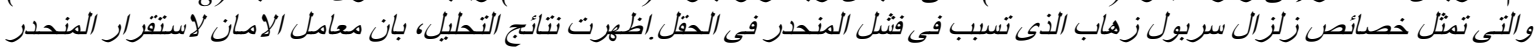

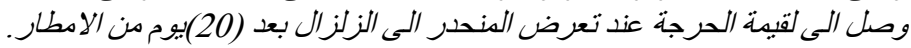

(الكلمات الدالة:

المنحر الابيس لسد دربنديخان, الامطار , الهزة الارضية. 